\title{
The Examination of Teacher Candidates' Selfishness Levels Regarding Sportive Activity and Different Variables
}

\author{
Erdogan Tozoglu ${ }^{1}$ \\ Murat Ozan ${ }^{2 \rtimes(i) ~}$
}

'Assoc. Dr., Ataturk University, Department of Physical Education and Sports, Turkey. Email:etozoglu@hotmail.com Tel: 05396647125

${ }^{2}$ Research Assistant Ataturk University, Department of Physical Education and Sports, Turkey.

Email:muratozan25@hotmail.com Tel:0506947058s

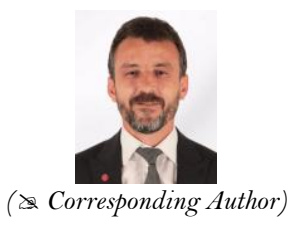

\begin{abstract}
The aim of this study is to the examination of teacher candidates' selfishness levels regarding sportive activity and different variables the study was conducted on 295 teacher candidates, 109 female and 186 male, who were educated in Erzurum Ataturk University, Kazim Karabekir faculty of education, in 2018-2019 academic year and voluntarily participated in the research. In the study, "The Selfishness Questionnaire: Egocentric, Adaptive, and Pathological Forms of Selfishness " was used which was developed by Adrian and Uh (2018) adapted to Turkish and analyzed for reliability and validity by Yllmaz (2018). Frequency analysis was used to determine demographic characteristics, and $\mathrm{T}$ test was used to examine the relationship between two independent variables and selfishness, analysis of variance was used to examine the relationship between more than two variables and selfishness. When the findings of the study were evaluated, it was seen that the pathological selfishness levels of female students were lower than male students. As a result of the findings, it is noticeable that the level of selfishness increases in parallel as the age level increases. The remarkable result here is, the level of selfishness increases in parallel as the time to do sportive activity increases. It is thought that, for students, sporting activity in their daily lives makes possible to increase their interaction with other students and therefore to focus on team or group goals rather than personal goals.
\end{abstract}

Keywords: Physical education, Teacher candidates, Spotive activity, Selfishness.

Citation | Erdogan Tozoglu; Murat Ozan (2020). The Examination of Teacher Candidates' Selfishness Levels Regarding Sportive Activity and Different Variables. Asian Journal of Education and Training, 6(1): 110-116

History:

Received: 25 November 2019

Revised: 15 January 2020

Accepted: 13 February 2020

Published: 9 March 2020

Licensed: This work is licensed under a Creative Commons Attribution 3.0 License (cc)

Publisher: Asian Online Journal Publishing Group
Acknowledgement: Both authors contributed to the conception and design of the study.

Funding: This study received no specific financial support.

Competing Interests: The authors declare that they have no conflict of interests.

Transparency: The authors confirm that the manuscript is an honest, accurate, and transparent account of the study was reported; that no vital features of the study have been omitted; and that any discrepancies from the study as planned have been explained.

study as planned have been explained.
Ethical: This study follows all ethical practices during writing.

\section{Contents}

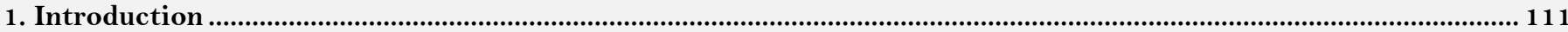

2. Method...

References. 


\section{Contribution of this paper to the literature}

This study contributes to the existing literature by examining of teacher candidates' selfishness levels regarding sportive activity and different variables.

\section{Introduction}

The totality of physical activities, which aim at the balanced development of human organism without disrupting its integrity, support the individual's physical, spiritual and intellectual development and aim at raising the individual as a person who is beneficial to the society s/he lives in and him/herself is defined as "physical education" (Açak, 2006). According to Kirchner and Fishburne (1995) physical education is the process of gaining positive behaviors in physical, mental and social terms through muscle activities (Kirchner and Fishburne, 1995). Sports is a "competitive, solidarist and cultural term, that is socializing and that improves the soul and physics, which the individual performs while transforming his/her natural environment into human environment, within the framework of some rules that improve the abilities she gained, either with or without a vehicle, individually or with a group, in his/her free time or in a way that takes all his/her time." (Arac1, 2006). According to another definition, sports is a group of activities that has specific goals and rules, that is associated with technical methods, that meets the needs of pleasure and enthusiasm of the audience as well as those who play, binding viewers and athletes together (Dogan, 2005). The general aim of physical education and sports is to help increase the mobility of each student by providing the education of children with physical activities. It also aims to contribute to children's physical, mental, social and emotional development. In this context, it can be said that physical education is a lifestyle that aims to contribute to the participants' development, knowledge levels, attitudes, movement and motor skills through physical activities and requires continuity in physical context (Demirhan and Altay, 2001).

Selfishness can be defined as acting by considering only one's own wishes and needs, without consideration or care of others and sometimes by disregarding consequences that might be harmful to others (Ronald, 2016). Selfishness is too complex to be explained with a single approach; it is a property that is related to biological features, personality, cognitive and emotional processes, socialization experience, culture and social contexts (Lam, 2012). Insecure bonds created by selfishness, lack of empathy, and reduced self-sacrifice greatly harm the social structure (Gilbert, 2018). A selfishness characteristic that dominates the individual's life is seen by some researchers as a sign of the path that leads to psychopathy and antisocial behavior disorder (Rustin, 2015). There are other authors who relate the source of the socio-economic problems we experience in the world to the increase of our selfishness (Handy, 2002). Those with this viewpoint relate the reason behind the increase in the conflict between countries, hunger and poverty to the increase of selfish personalities (Mintzberg et al., 2002). There are also researchers who think that selfishness is an important epidemic that may even bring an end to the world, because it is not sufficiently emphasized, researched and discussed (Cunningham, 2015). One of the most studied topics on this subject is the studies that seek the relationship between sports and selfish personality (Bayrak et al., 2015; Parlakkılıc and Tazegül, 2016). Despite both its individual and social importance, little research has been done on the personality traits of selfishness, partly due to the absence of an assessment tool (Adrian and Uh, 2018).

\section{Method}

\subsection{Research Model}

Descriptive survey model was used in this research. The descriptive survey model is a research model that aims to determine the presence or degree of two or more variables together. It would not be correct to interpret the relationships detected by scanning as a true cause-effect relationship; however, if the situation in one variable is known by providing some clues in that direction, it can yield to useful results in predicting the other (Karasar, 1991).

\subsection{Study Group}

The study group consisted of 295 students, 109 of which were females and 186 males who were studying at the Kazım Karabekir Education Faculty in Erzurum Ataturk University in the 2018-2019 academic year. The frequency and percentage distributions regarding students' demographic characteristics and their state of performing sports activities are shown in Table 1 and Table 2.

Table-1. The distribution of the demographic characteristics of individuals participating in the research.

\begin{tabular}{l|l|c|c}
\hline \multicolumn{2}{l|}{ Variable } & $\mathbf{n}$ & $\mathbf{\%}$ \\
\hline \multirow{2}{*}{ Gender } & Female & 109 & 36.9 \\
\cline { 2 - 4 } & Male & 186 & 63.1 \\
\hline \multirow{4}{*}{ Age } & Under the age of 20 & 112 & 38.0 \\
\cline { 2 - 4 } & Between 21-23 Years Old & 143 & 48.5 \\
\cline { 2 - 4 } & Above the age of 24 & 40 & 13.6 \\
\hline \multirow{3}{*}{ Family Structure } & Nuclear Family & 200 & 67.8 \\
\cline { 2 - 4 } & Extended Family & 15 & 27.1 \\
\cline { 2 - 4 } & Broken Family & 295 & 5.1 \\
\hline Total & & 100.0
\end{tabular}


Table-2. The sports activity status of individuals participating in the research.

\begin{tabular}{|c|c|c|c|}
\hline \multicolumn{2}{|l|}{ Variable } & \multirow{2}{*}{$\begin{array}{c}\mathbf{n} \\
262 \\
\end{array}$} & \multirow{2}{*}{$\begin{array}{c}\% \\
88.8 \\
\end{array}$} \\
\hline 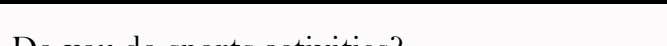 & Yes & & \\
\hline Do you do sports activities? & No & 33 & 11.2 \\
\hline \multirow{3}{*}{ What kind of sports activity do you do? } & Team Sport & 115 & 39.0 \\
\hline & Both of them & 28 & 9.5 \\
\hline & I do not. & 33 & 11.2 \\
\hline \multirow{3}{*}{ How many years have you been doing sports? } & Between 3-4 years & 116 & 39.3 \\
\hline & 5 years and above & 99 & 33.6 \\
\hline & I do not. & 33 & 11.2 \\
\hline \multirow{2}{*}{ What is your aim of doing sports activities? } & Social activity & 150 & 50.8 \\
\hline & Occupation & 31 & 10.5 \\
\hline
\end{tabular}

\subsection{Data Collection Tools}

In the study, a form with two sections was used as data collection tool. The first part consists of the personal information form developed in order to determine the gender, age, family structures, state of performing sports activities, types, duration and objectives of the of sports activities performed by students. In the second part, there is the Selfishness Scale, which is adapted to Turkish by Yllmaz (2018) and the validity and reliability analyses of which are made, is developed by Adrian and Uh (2018) and consists of three sub-dimensions being "Adaptive, Egocentric and Pathological Selfishness".

\subsection{Data Collection}

The students were given detailed information about the purpose and filling of the data collection tool before the data collection tool was distributed. The research was conducted in a classroom environment and the data collection tool was distributed only to those who want to fill in the questionnaire based on the principle of voluntary participation.

\subsection{Data Analysis}

SPSS 25 packaged software was used in data analysis. Before proceeding to the analysis of the data obtained within the scope of the research, it was determined whether the data showed a normal distribution by examining the skewness and kurtosis coefficients. When the skewness and kurtosis coefficients are analyzed, it is seen that the data set within the limits $(-1.5$ and +1.5$)$ specified by Tabachnick and Fidell (2015) has a normal distribution Table 3. In the analysis of the data, frequency distribution was used in determining demographic characteristics, $\mathrm{T}$ test (Independent Sample t test) was used in order to examine the differentiation between two independent variables and the variable of selfishness and Anova Variance analysis tests were used in order to examine the differentiation between more than two variables and the variable of selfishness. The difference between the variables was interpreted on the basis of p.0.05 significance level.

Table-3. Normality distribution test results.

\begin{tabular}{l|c|c|c|c}
\hline Variable & $\begin{array}{c}\text { Adaptive } \\
\text { Selfishness }\end{array}$ & $\begin{array}{c}\text { Egocentric } \\
\text { Selfishness }\end{array}$ & $\begin{array}{c}\text { Pathological } \\
\text { Selfishness }\end{array}$ & Selfishness Level \\
\hline $\mathrm{N}$ & 295 & 295 & 295 & 295 \\
\hline Mean & 9.93 & 9.78 & 8,09 & 27.80 \\
\hline Median & 10.00 & 9.00 & 8.00 & 26.00 \\
\hline Mode & 8.00 & 8.00 & 7.00 & 7.19 \\
\hline Std. Deviation & 2.80 & 2.94 & 2,34 & 51.70 \\
\hline Variance & 7.82 & 8.62 & 5,48 & .614 \\
\hline Skewness & .420 & .683 & .602 & .142 \\
\hline Std. Error of Skewness & .142 & .142 & .142 & -.569 \\
\hline Kurtosis & -.840 & -.369 & -.473 & .283 \\
\hline Std. Error of Kurtosis & .283 & .283 & .283 & 29.00 \\
\hline Range & 11.00 & 12.00 & 10.00 & 17.00 \\
\hline Minimum & 6.00 & 6.00 & 5.00 & 46.00 \\
\hline Maximum & 17.00 & 18.00 & 15.00 & \\
\hline
\end{tabular}

\section{Findings}

In this section, this study statistically analyzes and comments of the data obtained as a result of the application of the data collection tool (Selfishness Scale). 
Table-4. The results of the independent group $t$ test conducted to determine whether the scores of selfishness sub-dimensions differ according to the gender variable of the students.

\begin{tabular}{|c|c|c|c|c|c|c|}
\hline Selfishness Scale Sub-Dimensions & Gender & $\mathbf{n}$ & $\mathbf{x}$ & $\mathbf{s}$ & $\mathbf{t}$ & $\mathbf{p}$ \\
\hline \multirow{2}{*}{ Adaptive Selfishness } & Female & 109 & 9.60 & 2.85 & \multirow{2}{*}{-1.567} & \multirow{2}{*}{.118} \\
\hline & Male & 186 & 10.12 & 2.75 & & \\
\hline Egocentric Selfishness & Male & 186 & 9.93 & 2.84 & -1.150 & .251 \\
\hline \multirow{2}{*}{ Pathological Selfishness } & Female & 109 & 7.68 & 2.29 & \multirow{2}{*}{-2.315} & \multirow{2}{*}{.021} \\
\hline & Male & 186 & 8.33 & 2.35 & & \\
\hline
\end{tabular}

In Table 4, after the $t$ test analysis between students' gender and selfishness scale sub-dimension scores. it was determined that there was a significant difference in the pathological sub-dimension at $p<.050$ level. $(t=-2.315 . p>$. 021). . In the pathological sub-dimension. it is observed that the female students' pathological selfishness levels are lower than that of male students. In other sub-dimensions. no significant difference was found in terms of the gender variable.

Table-5. The results of the one-way variance analysis (Anova) test conducted to determine whether the scores of the selfishness scale subdimensions differ according to the age variable of the students.

\begin{tabular}{|c|c|c|c|c|c|c|}
\hline Selfishness Scale Sub-Dimensions & AGE & n & $\mathbf{x}$ & $\mathbf{s}$ & f & $\mathbf{p}$ \\
\hline \multirow{3}{*}{ Adaptive Selfishness } & Under the age of 20 & 112 & 9.77 & 2.81 & \multirow{3}{*}{2.404} & \multirow{3}{*}{.092} \\
\hline & Between 21-23 & 143 & 9.80 & 2.82 & & \\
\hline & Total & 295 & 9.93 & 2.80 & & \\
\hline \multirow{3}{*}{ Egocentric Selfishness } & Under the age of 20 & 112 & 9.87 & 2.97 & \multirow{3}{*}{.673} & \multirow{3}{*}{.511} \\
\hline & Between 21-23 & 143 & 9.60 & 2.85 & & \\
\hline & Total & 295 & 9.78 & 2.93 & & \\
\hline \multirow{4}{*}{ Pathological Selfishness } & Under the age of 20 & 112 & 7.84 & 2.29 & \multirow{4}{*}{2.376} & \multirow{4}{*}{.095} \\
\hline & Between 21-23 & 143 & 8.01 & 2.22 & & \\
\hline & Above the age of 24 & 40 & 8.78 & 2.80 & & \\
\hline & Total & 295 & 8.09 & 2.34 & & \\
\hline
\end{tabular}

İn Table 5, after the one-way analysis of variance (Anova / Tukey) test conducted to compare the selfishness sub-dimension levels of students at different age levels. it was determined that there was no difference in $\mathrm{p}<.050$ level.

Table-6. The results of the one-way variance analysis (Anova) test conducted to determine whether the scores of the selfishness scale subdimensions differ according to the family structure variable of the students.

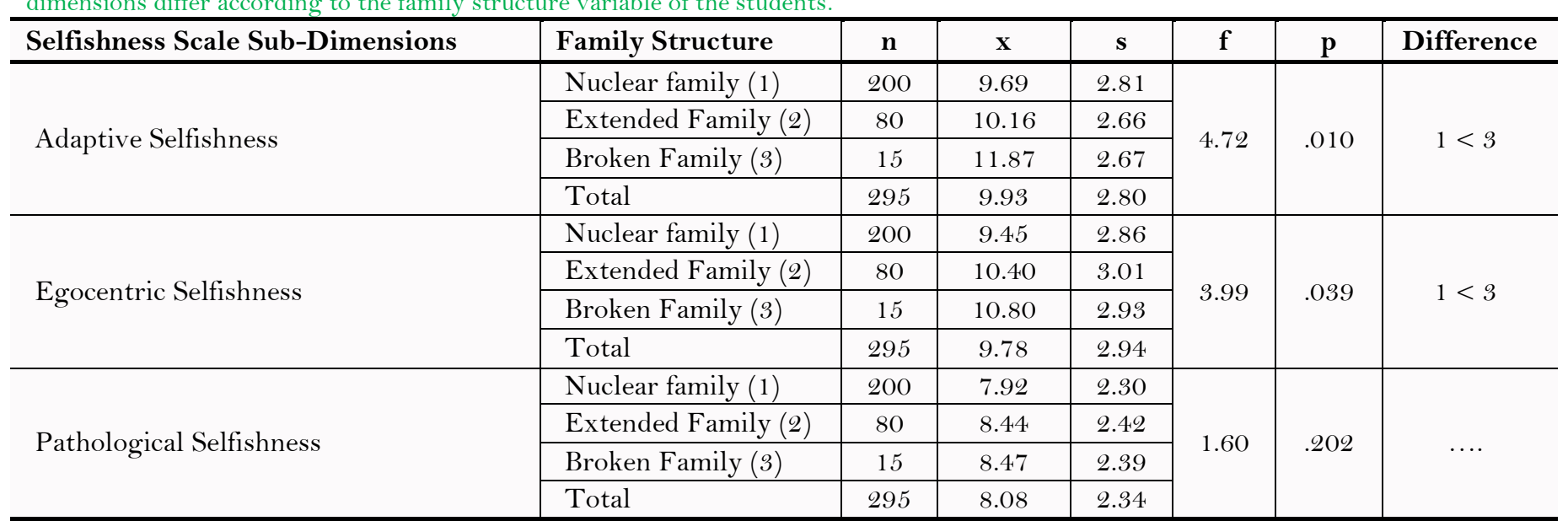

İn Table 6, after the one-way analysis of variance (Anova / Tukey) test conducted to compare the selfishness sub-dimension levels of students with different family structures. it was determined that there was a difference in the sub-dimensions of adaptive selfishness and egocentric selfishness at the level of $p<050$. It is observed that the selfishness levels of the students in the nuclear family structure in these dimensions with significant differences are lower than the students in the fragmented family structure.

Table-7. The results of the independent group t test conducted to determine whether the scores of selfishness sub-dimensions differ according to the gender variable of the students' performing sports activity.

\begin{tabular}{|c|c|c|c|c|c|c|}
\hline Selfishness Scale Sub-Dimensions & Do you do sports activities? & $\mathbf{n}$ & $\mathbf{x}$ & $\mathbf{s}$ & $\mathrm{t}$ & p \\
\hline \multirow{2}{*}{ Adaptive Selfishness } & Yes & 262 & 9.90 & 2.77 & \multirow{2}{*}{-.353} & \multirow{2}{*}{.725} \\
\hline & No & 33 & 10.01 & 3.03 & & \\
\hline Egocentric Selfishness & No & 33 & 10.52 & 3.43 & -1.530 & .127 \\
\hline \multirow{2}{*}{ Pathological Selfishness } & Yes & 262 & 8.11 & 2.33 & \multirow{2}{*}{.544} & \multirow{2}{*}{.587} \\
\hline & No & 33 & 7.88 & 2.42 & & \\
\hline
\end{tabular}

It was determined that there was no significant difference in $\mathrm{p}<$. O50 level after the t test analysis conducted between the students' state of doing sports activities and the selfishness scale sub-dimension scores. 
Table-8. The results of the one-way variance analysis (Anova) test conducted to determine whether the scores of the selfishness scale subdimensions differ according to the variable of the type of the sports activity that the students have been performing.

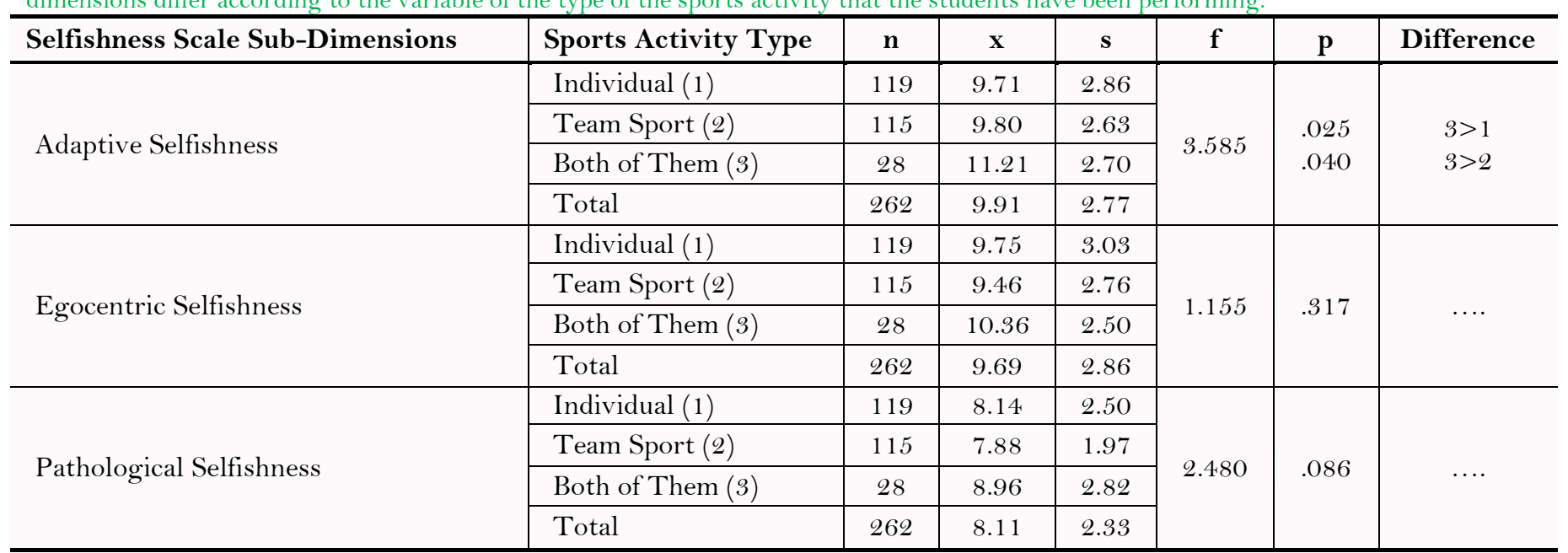

In Table 8, after the one-way analysis of variance (Anova / Tukey) test conducted to compare the sports activity type that the students have been performing and their selfishness sub-dimension levels. a significant difference was found at $\mathrm{p}<.050$ level. in the adaptive selfishness sub-dimension. It is observed that the adaptive selfishness level of the students who do both sports together is higher than that of students who do only individual and team sports. In other sub-dimensions. no significant difference was found in terms of the sports activity type variable.

Table-9. The results of the one-way variance analysis (Anova) test conducted to determine whether the scores of the selfishness scale subdimensions differ according to the variable of the duration of the sports activity that the students have been performing.

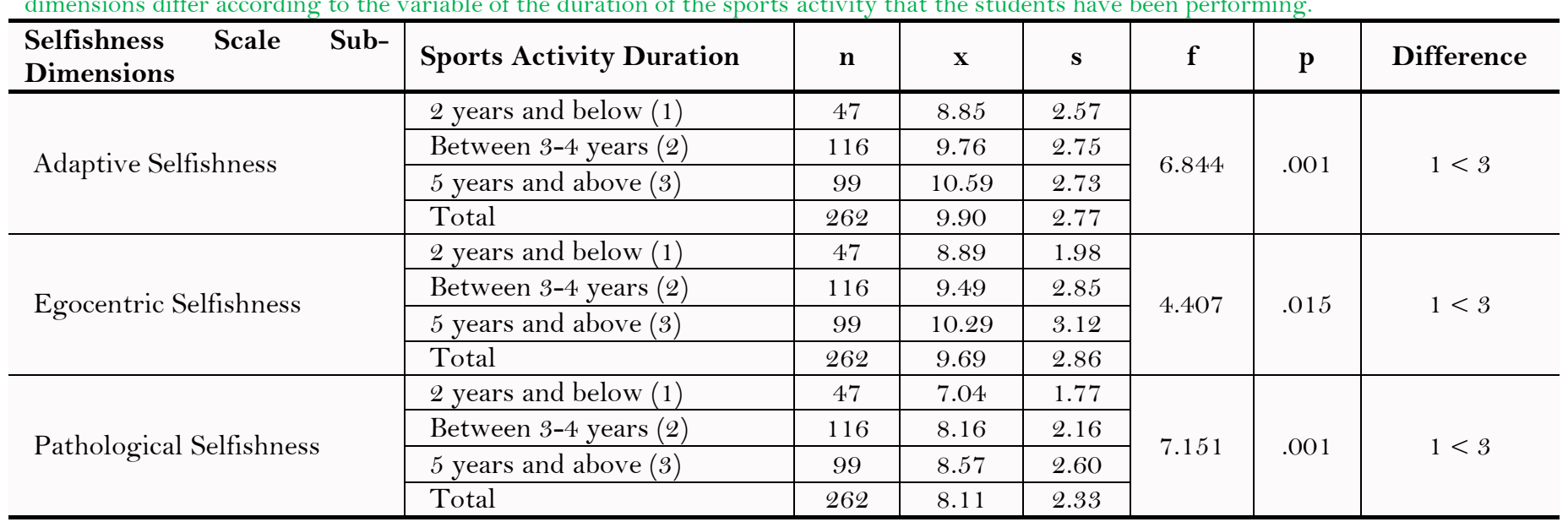

İn Table 9, after the one-way analysis of variance (Anova / Tukey) test conducted to compare students' duration of doing sports activities and selfishness sub-dimension levels. it was determined that there was a difference in all dimensions at $\mathrm{p}<$. 050 level. It is observed that the selfishness levels of students who performed sports activities for 5 years or more are higher than those who performed sports activities for 2 years or less.

Another remarkable result is the observation of the result that the level of selfishness increases in parallel with the duration of doing sports activities.

Table-10. The results of the one-way variance analysis (Anova) test conducted to determine whether the scores of the selfishness scale subdimensions differ according to the variable of the goal of the sports activity that the students have been performing.

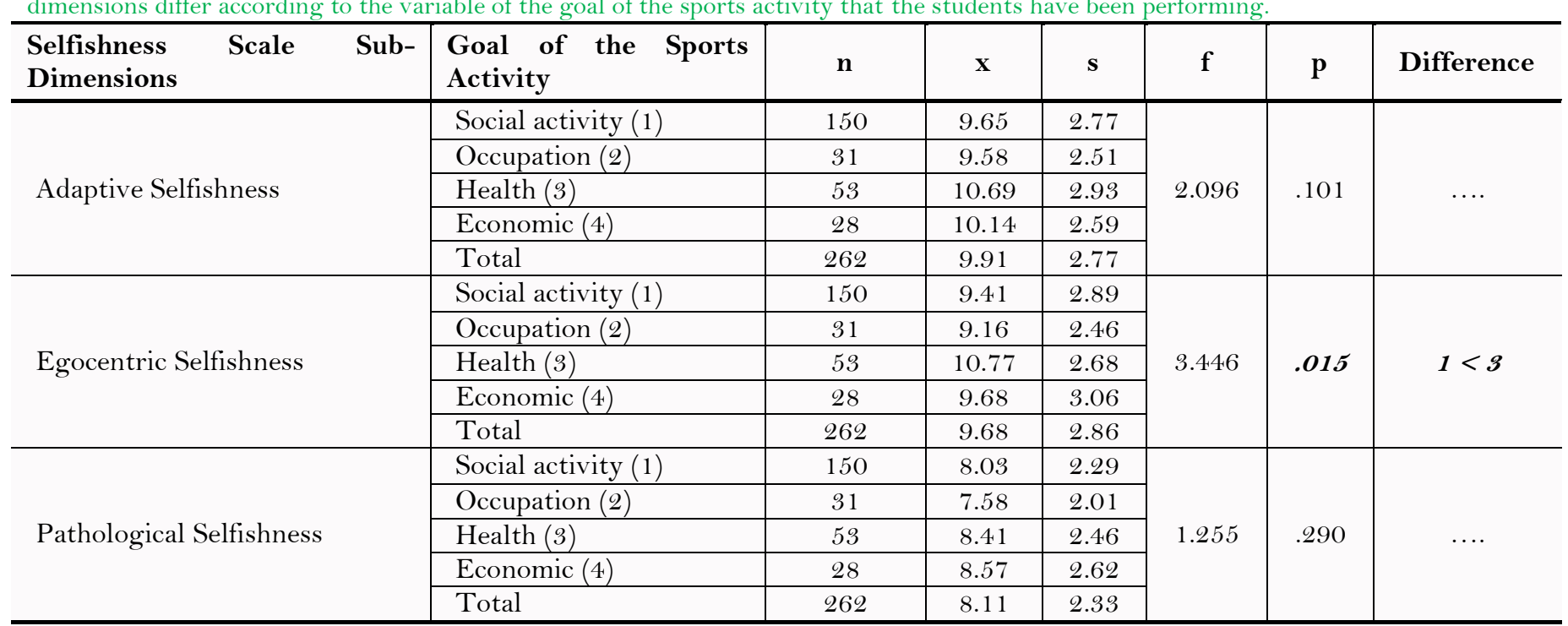

İn Table 10, after the one-way analysis of variance (Anova / Tukey) test conducted to compare students' goal of doing sports activities and selfishness sub-dimension levels. it was determined that there was a difference at the egocentric sub-dimension at $\mathrm{p}<$. 050 level. In the egocentric sub-dimension, it is observed that the selfishness level 
of the students who do sports activities for social activity purposes is lower than that of those who do sports activities for health purposes. In other sub-dimensions, no significant difference was found in terms of the sports activity goal variable.

\section{Conclusion}

When the findings of the study were evaluated, it was determined that there was a significant difference in the gender and pathological sub-dimension of the students and female students' pathological selfishness levels were found to be lower than that of male students. In the literature, in the study conducted by Seguino et al. (1996) to investigate students' tendency to benefit from public goods without paying a fee (free rider), it was concluded that gender may affect the tendency to be selfish. In the study conducted by Duda (1989) on university and high school athletes performing individual and team sports, it was stated that men are more ego oriented than women. Unlike the results of the study, it was stated that gender did not have any effect on selfishness in the study conducted by Arınç (2019) on university students.

It was determined that there was a significant difference between the family structures of the students participating in the study and the total scores of adaptive selfishness, egocentric selfishness and selfishness. The selfishness levels of the students in the nuclear family structure in these dimensions with significant differences were found to be lower than the students in the broken family structure. In the family, which is the first social unit where people share their griefs and joys, the parties cannot use their time, labor and interests only for themselves. With this aspect, it is an institution that socializes the person and steers him/her away from being selfish (Erkal, 1993).

When the status of performing sports activities is analyzed, it is observed that the selfishness level of the students who perform a low level of sports activity is lower than that of the students who do not perform sports activities. Again, it is observed that there is a significant difference in the type of the sports activity that the students have been performing and the sub-dimension of adaptive selfishness, and that the adaptive selfishness levels of students who perform both sports are only higher than that of those who perform only individual or team sports.

In the literature, in the study conducted by Porcerelli and Sandler (1995) it was found that self-indulgence levels of weightlifting and bodybuilding athletes using steroids were higher than those who did not use steroids. The fact that the athlete has high life satisfaction may reveal his desire to maintain his skill and to be superior to other athletes. Therefore, high satisfaction with life brings along being a star athlete and recognition (Papaioannou, 1994; Toros and Yetim, 2000). This situation can be explained by the fact that the selfishness levels of the individuals who do both sports are higher than that of the students who perform only individual or team sports.

When the questionnaire results are analyzed, considering students' duration of performing sports activities in all dimensions, it is observed that the selfishness levels of students who have performed sports activities for 5 years or more are higher than that of students who have performed sports activities for 2 years or less. Another remarkable result is the observation of the result that the level of selfishness increases in parallel with the duration of doing sports activities. As a matter of fact, in many studies, it has been found that self-interested individuals attach importance to their appearance (Emmons, 1984; Jackson et al., 1992; Davis et al., 2001). Also in a study conducted by Davis (1992) it was stated that narcissistic individuals focused on their body appearance and used exercise as a tool for their visuality. That students who have been performing sports for 5 years or more have a proportionate and well-developed physique may be seen as one of the biggest factors behind their excessively developed selfishness levels.

When physical education and sports are considered as activities performed both individually and as a team and accordingly, in the light of the fact that it positively affects the social and spiritual development of the person or people, it is thought that if students perform sports activities and start seeing it as a part of their lives, they will be less affected by different forms of selfishness. Atar (2017) emphasized the importance of the relationship between the benefits of physical education lesson to the student and the weekly number and duration of the applications. This view supports the conclusion that students who perform low levels of sports activity have lower selfishness levels than students who do not perform sports activities. However, according to the findings obtained at the end of the study, the conclusion that the level of selfishness increases in parallel with the duration of doing sports activity, contradicts this view.

That physical education and sports are performed voluntarily and tastefully is one of the important points in achieving the goals of physical education and sports. When the findings obtained in the study are interpreted, that individuals who work to succeed and are focused on their goal in physical education and sports are individualized and have higher selfishness levels for the sake of achieving their goals can be considered as a natural result. Based on the conclusion that the selfishness level of the students performing sports activities for the purpose of social activity is lower than that of the students performing sports activities for health purposes, that students perform physical activities in their social environments is considered important in terms of enabling an increase in the interaction between them and accordingly their serving team interests rather than personal interests.

\section{References}

Açak, M., 2006. Handbook of physical education teacher. Istanbul: Morpa Culture Publications.

Adrian, R. and S. Uh, 2018. The selfishness questionnaire: Egocentric, adaptive, and pathological forms of selfishness. Journal of Personality Assessment: 1-12.

Aracı, H., 2006. Physical education in schools. 6th Edn., Ankara: Nobel Publishing.

Arınç, M., 2019. Modernity and selfishness. Unpublished Master's Thesis. The University of Selçuk, Institute of Social Sciences: Konya.

Atar, Ö., 2017. Comparison of narcissism levels of students who do sports and who do not do sports. European Journal of Education Studies, 3(12): 413-420.

Bayrak, E., A. Gaçar, E. Nacar and K.Y. Aytaç, 2015. Investigation of narcissistic personality traits of education and sports school students from me. Academic Journal of Social Research, 3(14): 249-261.

Cunningham, D., 2015. Living in the age of selfishness with. CBR.com. Available from https://www.cbr.com/living-in-the-age-ofselfishness-with-darryl-cunningham/ [Accessed 20.03.2018]. 
Davis, C., 1992. Body image, dieting behaviors, and personality factors: A study of high-performance female athletes. International Fournal of Sport Psychology, 23(3): 179-192.

Davis, C., M. Dionne and B. Shuster, 2001. Physical and psychological correlates of appearance orientation. Personality and Individual Differences, 30(1): 21-30.Available at: https://doi.org/10.1016/s0191-8869(00)00006-4.

Demirhan, G. and F. Altay, 2001. Attitude scale of high school first graders towards physical education and sport II. Hacettpe Journal of Sport Sciences, 12(2): 9-20.

Dogan, O., 2005. Sports psychology. Adana: Nobel Publishing.

Duda, J.L., 1989. Relationship between task and ego orientation and the perceived purpose of sport among high school athletes. Journal of Sport and Exercise Psychology, 11(3): 318-335.Available at: https://doi.org/10.1123/jsep.11.3.318.

Emmons, R.A., 1984. Factor analysis and construct validity of the narcissistic personality inventory. Journal of Personality Assessment, 48(3): 291-300.Available at: https://doi.org/10.1207/s15327752jpa4803_11.

Erkal, M.E., 1993. Turkish family structure and some issues. Journal of Sociology Conferences of Istanbul University, 1(24): 15-21.

Gilbert, O.M., 2018. Altruism or association? Proceedings of the National Academy of Scien-ces.

Handy, C., 2002. The hungry spirit: New thinking for a new world: Beyond capitalism - a quest for purpose in the modern world. London: Arrow Books Ltd. pp: 88.

Jackson, L.A., K.S. Ervin and C.N. Hodge, 1992. Narcissism and body image. Journal of Research in Personality, 26(4): 357-370.Available at: https://doi.org/10.1016/0092-6566(92)90065-c.

Karasar, N., 1991. Scientific research techniques. 1th Edn., Ankara: Sanem Publishing.

Kirchner, G. and G.J. Fishburne, 1995. Physical education for elementary school children. USA: Brown \& Benchmark.

Lam, C.M., 2012. Prosocial involvement as a positive youth development construct: A conceptual review. The Scientific World Journal, 2012.Available at: $10.1100 / 2012 / 769158$

Mintzberg, H., R. Simons and K. Basu, 2002. Beyond selfishness. MIT Sloan Management Review, 44(1): 67-74.

Papaioannou, A., 1994. Development of a questionnaire to measure achievement orientations in physical education. Research Quarterly for Exercise and Sport, 65(1): 11-20.Available at: https://doi.org/10.1080/02701367.1994.10762203.

Parlakkılıc, S. and U. Tazegül, 2016. Determination of the relationship between moral maturity and narcissism levels of individuals doing sports. Academic Journal of Social Research(38): 303-310.

Porcerelli, J.H. and B.A. Sandler, 1995. Narcissism and empathy in steroid users. American Journal of Psychiatry, 152(11): 16721674.Available at: https://doi.org/10.1176/ajp.152.11.1672.

Ronald, D., 2016. Reflections on selfishness and self-interest. Journal of Financial Service Professionals, 70(3): 26-29.

Rustin, M., 2015. The good life: Wellbeing and new science of altruism, selfishness and immorality. Psychodynamic Practice, 21(2): 188191.Available at: 10.1080/14753634.2015.1016652.

Seguino, S., T. Stevens and M. Lutz, 1996. Gender and cooperative behavior: Economic man rides alone. Feminist Economics, 2(1): 121.Available at: https://doi.org/10.1080/738552683.

Tabachnick, B.G. and L.S. Fidell, 2015. Use of multivariate statistics (Translated: Baloğlu, M.). Ankara: Nobel Publishing.

Toros, T. and U. Yetim, 2000. Adaptation preliminary study of the motivational (motivational) climate scale perceived in spor ts for Turkish athletes. International Sports Sciences Congress. May 11-13, Istanbul.

Yllmaz, H., 2018. Selfishness scale: Measuring adaptive, egocentric and pathological forms of selfishness. Academic Journal of Social Research, 6(74): 45-57. 